\title{
Diagnosing MRI-negative autoimmune diseases
}

Carsten Finke, MD

Neurol Neuroimmunol Neuroinflamm 2018;5:e457. doi:10.1212/NXI.0000000000000457

The diagnosis of MS requires demonstration of disease dissemination in space and time and is based on diagnostic criteria such as the recently revised McDonald criteria. ${ }^{1}$ With their 2001 revision, the McDonald criteria formally have included MRI in the diagnostic workup of patients with suspected MS. ${ }^{2}$ Since then, the relevance of MRI for diagnosis and disease monitoring has further increased owing to continuous improvements of MRI scanners and sequences. Nevertheless, there is a clinicoradiologic dissociation in MS, i.e., some patients with high lesion load experience a relatively mild disease course, whereas others with few abnormalities on conventional MRI fare far worse. In a few patients who do fulfill the current McDonald Criteria and who have received a tentative diagnosis of MS, brain MRI remains unremarkable. This raises the obvious question of whether such MRI-negative patients indeed have MS or another autoimmune CNS disorder.

In this issue of Neurology ${ }^{\circledR}$ Neuroimmunology \& Neuroinflammation, Takewaki et al. ${ }^{3}$ report on 11 patients identified from a single MS center cohort of 550 patients who fulfilled the 2010 McDonald criteria, but had normal conventional MRI of the brain and the spinal cord. These patients had a mean age of 41.5 years, a mean disease duration of 12.6 years, and a median Expanded Disability Status Scale score of 6, indicating severe disability. Clinically, patients presented with involvement of the pyramidal system and visual impairment as well as with somatosensory, autonomic, and cognitive symptoms. All patients responded to immunotherapy with IV methylprednisolone and/or plasmapheresis. Diffusion tensor imaging (DTI) revealed extensive white matter abnormalities, and the frequency of plasmablasts in the peripheral blood was significantly increased in these patients. The authors conclude that the identified patients might have a distinct autoimmune disease entity that they propose to be called "Normal-appearing Imaging-associated, Neuroimmunologically Justified, Autoimmune Encephalomyelitis (NINJA)."

Current diagnostic criteria for MS allow for an early diagnosis and treatment of the patients, facilitated by a high sensitivity of the criteria. However, the specificity of these criteria is only modest. ${ }^{2}$ In addition, MRI criteria were developed to identify patients at risk for MS and not to differentiate MS from other conditions. These factors can contribute to misdiagnosing patients with MS, especially when white matter abnormalities associated with migraine or small vessel ischemic disease are present. ${ }^{4}$ In contrast, Takewaki et al. report on patients with disorders mimicking MS that do fulfill the diagnostic criteria, but have a normal conventional MRI. In addition, the CSF cell count and immunoglobulin $\mathrm{G}$ index were normal, and oligoclonal bands were absent in these patients. Electrophysiologic studies showed abnormalities in only 4 of 8 studied patients. Given this discrepancy between multifocal clinical presentation and protracted disease courses on the one hand and negative MRI and CSF findings on the other, these patients are additionally at risk of being diagnosed with somatoform disorders. Clearly, good clinical judgment should guide (tentative) diagnosis and early initiation of immunotherapy in these patients.

What do these patients suffer from then? The extensive diagnostic workup that included exclusion of a wide range of other autoimmune, infectious, degenerative, and neoplastic

\author{
Correspondence \\ Dr. Finke \\ carsten.finke@charite.de
}

\section{RELATED ARTICLE}

Normal brain imaging accompanies neuroimmunologically justified, autoimmune encephalomyelitis

Page e456 
disorders, the clinical improvement after immunotherapy, and the increased plasmablast frequency indicate that these patients have an autoimmune-mediated disorder. The field of autoimmune neurology has seen a rapidly expanding number of newly identified neuroimmunologic disorders in the last 10-15 years, driven by the characterization of new clinical syndromes and the identification of pathogenic autoantibodies. ${ }^{5}$ This includes disorders such as anti-NMDA receptor encephalitis, anti-leucine-rich glioma-inactivated protein 1 encephalitis, or myelin oligodendrocyte glycoprotein (MOG)antibody-associated disease. ${ }^{6,7}$ Although the presence of antiMOG and anti-aquaporin-4 antibodies was excluded in the patients identified by Takewaki et al., they were not tested for other antibodies against neuronal cell surface antigens. Without identification of a specific biomarker common to these patients, it is conceivable that they represent a heterogeneous cohort composed of different clinical entities with distinct underlying immunopathogenetic mechanisms.

MRI was performed on a $3 \mathrm{~T}$ magnetic resonance scanner using 3D T1-weighted and fluid-attenuated recovery sequences. In contrast to unremarkable conventional MRI studies, the authors report extensive white matter abnormalities that were detected using DTI. Specifically, decreased fractional anisotropy was observed throughout the brain and might represent a correlate of the reported clinical symptoms. Of note, this imaging pattern is reminiscent of MRI changes in anti-NMDA receptor encephalitis: The majority of these patients similarly have a normal conventional MRI despite the presence of severe symptoms-and DTI analyses likewise identified widespread white matter damage (including decreased fractional anisotropy) that correlated with disease severity. ${ }^{8}$ In addition, large-scale functional network disturbances were identified in patients with anti-NMDA receptor encephalitis that correlated with distinct clinical symptoms such as memory impairment or psychotic symptoms. ${ }^{9}$ This remarkable link could point to common disease mechanisms and thus calls for future advanced imaging investigations, especially in patients with normal conventional MRI.
In summary, the relevant work by Takewaki et al. identified MRI-negative patients with an MS mimicking disorder that is likely of autoimmune origin. This study hopefully stimulates other groups to identify similar patients and investigate them ideally in prospective study designs that include extended autoimmune diagnostic workup and advanced structural and functional imaging. In the future, the majority of these patients likely can be diagnosed based on a molecular classification. $^{10}$

\section{Study funding}

No targeted funding reported.

\section{Disclosure}

C. Finke has received research support from Euroimmun AG, the German Ministry of Education and Research (BMBF), and the Berlin School of Mind and Brain. Full disclosure form information provided by the authors is available with the full text of this article at Neurology.org/NN.

\section{References}

1. Thompson AJ, Banwell BL, Barkhof F, et al. Diagnosis of multiple sclerosis: 2017 revisions of the McDonald criteria. Lancet Neurol 2018;17:162-173.

2. Filippi M, Preziosa P, Meani A, et al. Prediction of a multiple sclerosis diagnosis in patients with clinically isolated syndrome using the 2016 MAGNIMS and 2010 McDonald criteria: a retrospective study. Lancet Neurol 2017;17:133-142.

3. Takewaki D, Lin Y, Sato W, et al. Normal brain imaging accompanies neuroimmunologically justified, autoimmune encephalomyelitis. Neurol Neuroimmunol Neuroinflamm 2018;5:e456. doi: 10.1212/NXI.0000000000000456.

4. Solomon AJ, Bourdette DN, Cross AH, et al. The contemporary spectrum of multiple sclerosis misdiagnosis. Neurology 2016;87:1393-1399.

5. Dalmau J. The case for autoimmune neurology. Neurol Neuroimmunol Neuroinflamm 2017;4:e373. doi: 10.1212/NXI.0000000000000373.

6. Dalmau J. NMDA receptor encephalitis and other antibody-mediated disorders of the synapse. Neurology 2016;87:2471-2482.

7. Varley J, Vincent A, Irani SR. Clinical and experimental studies of potentially pathogenic brain-directed autoantibodies: current knowledge and future directions. J Neurol 2015;262:1081-1095.

8. Finke C, Kopp UA, Scheel M, et al. Functional and structural brain changes in anti-N-methyl-D-aspartate receptor encephalitis. Ann Neurol 2013;74:284-296.

9. Peer M, Prüss H, Ben-Dayan I, Paul F, Arzy S, Finke C. Functional connectivity of large-scale brain networks in patients with anti-NMDA receptor encephalitis: an observational study. Lancet Psychiatry 2017;4:768-774.

10. Pittock SJ. NMO spectrum disorders: clinical or molecular classification? Nat Rev Neurol 2016;12:129-130. 


\section{Neurology \\ Neuroimmunology \& Neuroinflammation}

Diagnosing MRI-negative autoimmune diseases

Carsten Finke

Neurol Neuroimmunol Neuroinflamm 2018;5;

DOI 10.1212/NXI.0000000000000457

This information is current as of April 2, 2018

\section{Updated Information \& Services}

References

Subspecialty Collections

Permissions \& Licensing

\section{Reprints}

including high resolution figures, can be found at:

http://nn.neurology.org/content/5/3/e457.full.html

This article cites 10 articles, 0 of which you can access for free at: http://nn.neurology.org/content/5/3/e457.full.html\#\#ref-list-1

This article, along with others on similar topics, appears in the following collection(s):

MRI

http://nn.neurology.org//cgi/collection/mri

Multiple sclerosis

http://nn.neurology.org//cgi/collection/multiple_sclerosis

Information about reproducing this article in parts (figures,tables) or in its entirety can be found online at:

http://nn.neurology.org/misc/about.xhtml\#permissions

Information about ordering reprints can be found online:

http://nn.neurology.org/misc/addir.xhtml\#reprintsus

Neurol Neuroimmunol Neuroinflamm is an official journal of the American Academy of Neurology.

Published since April 2014, it is an open-access, online-only, continuous publication journal. Copyright

Copyright $\odot 2018$ The Author(s). Published by Wolters Kluwer Health, Inc. on behalf of the American

Academy of Neurology. All rights reserved. Online ISSN: 2332-7812.

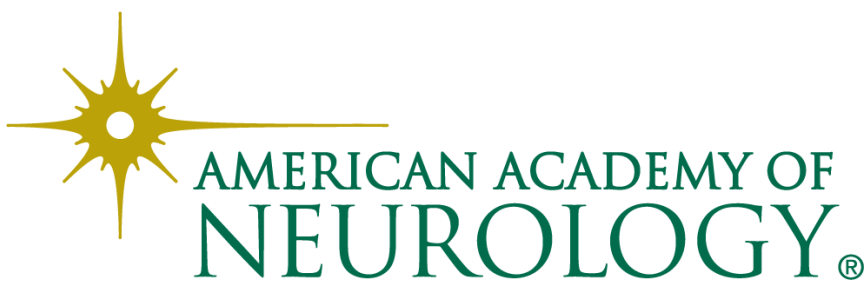

